\title{
Reducing post harvest losses of litchi by processing
}

\author{
SABBU SANGEETA* AND C.S. CHOPRA \\ Department of Food Science and Technology, G.B. Pant University of Agriculture and Technology, Pantnagar, U.S. NAGAR \\ (UTTARAKHAND) INDIA \\ Email : sangeeta_pantnagar@yahoo.com \\ *Author for Correspondence \\ Research chronicle : Received : 29.06.2015; Accepted : 30.11.2015
}

\begin{abstract}
SUMMARY :
Litchi (Litchi chinensis Sonn.) is a subtropical crop, non-climacteric and drupe or stone fruit. It is conical, heart shaped or spherical with a thick leathery, indehiscent pericarp at maturity. Litchi is known for its pleasant flavour and juicy pulp (aril) with attractive red colour pericarp. It is also an excellent source of vitamins and minerals. India with annual production of 483.3 thousand metric tons from an area of 74.4 thousand hectares, is the second largest producer of litchi next to China. Litchi fruit has great commercial potential in the domestic as well as global markets. It is very delicate fruit and highly perishable in nature. Under ambient conditions, it looses upto 7-11 per cent weight within one day after harvest due to water losses. The attractive bright red colour turns to unpleasant brown colour within 24-48 hours which drastically reduces marketability of fruit. Thus, these are considered as the major causes of post harvest losses of litchi. The browned or fresh litchi has tremendous potential in the processing industry as it may be utilized for extracting certain chemicals of industrial importance or may also be converted into value added food products. Certain free and glycosidically-bound volatile compounds that produce strong litchi-like fruity aroma can be extracted from litchi fruit. Innovative and value added products like cordial, squash, nectar, burfee, chutney, dehydrated litchi, pulp, osmo-syrup, wine and juice can be prepared from litchi. Litchi seeds can also be used for production of sesquiterpene glucosides, cyclopropyl-containing fatty acid glucoside and some antioxidants. The dried litchi peel after grinding and thermally activation can be used for removal of acid blue 25 dye from aqueous solutions which helps in treating industrial effluents containing dyes.
\end{abstract}

KEY WORDS : Reducing, Post harvest Losses, Litchi, Processing

How to cite this paper : Sangeeta, Sabbu and Chopra, C.S. (2015). Reducing post harvest losses of litchi by processing. Internat. J. Proc. \& Post Harvest Technol., 6 (2) : 184-189. 